\title{
How to Develop the Information and Knowledge Processing Competency of College Students of Humanities
}

\author{
Sung Kyu Yun ${ }^{1}$, Nan Young Kim², Hyung-ji Chang ${ }^{3}$ \\ ${ }^{1}$ Professor, English, Sun Moon University, Korea, sungkyu@sunmoon.ac.kr \\ ${ }^{2}$ Professor, Global Tourism, Sun Moon University, Korea, kyoung52@sunmoon.ac.kr \\ ${ }^{3}$ Professor, Global Tourism, Sun Moon University, Korea, maria07@sunmoon.ac.kr
}

Corresponding author: Hyung-ji Chang

\begin{abstract}
The present study is aimed at investigating the Knowledge and Information Processing Competency (KIPC) of Korean college students. A total of 238 students participating in Tourism English, English and Japanese language courses were measured by the KIPC scale and their demographical characteristics were analyzed in this study. The KIPC scale consists of three categories, which include knowledge and information collection, knowledge and information processing, and knowledge and information utilization. The three categories were divided into seven items; collection of knowledge and information is subdivided into setting a scope, media selection, and data judgment, knowledge and information processing is subdivided into analysis and interpretation and knowledge and information utilization is subdivided into production and presentation. The collected data were analyzed by T-test and ANOVA. The findings are summarized as follows. Firstly, the knowledge information collection capability was the highest with an average of 3.6, followed by knowledge information analysis capability and knowledge information utilization capability. Secondly, among the factors, students showed the strongest strength in selecting the medium or range for data collection, but the ability to extract important information from the collected data and interpret and present the results is a bit insufficient. Thirdly, there was no significant difference in KIPC according to the grades. However, knowledge and information competency according to the nationality was found to have significant differences. Finally, this paper concludes with pedagogical implications discussed in the study.
\end{abstract}

Keywords: Core Competency, Knowledge and Information Processing Competency, Knowledge and Information Collection, Knowledge and Information Itilization

\section{Introduction}

This study examines the Knowledge and Information Processing Competency (KIPC), which is a core competency in the era of the '4th Industrial Revolution' in the 21st century. and proposes various class activities to reinforce core competencies. In Korea, doing SNS, watching videos, taking online lectures and using ICT for information retrieval occupy a large proportion of time for college students in their studies and daily life. It is to be expected that the amount of knowledge information is increasing and the development of KIPC is encouraged. In this study, KIPC is defined as the ability to collect, analyze, and use knowledge information related to real life and employment and it is being established as a core competency in all university classes[1]. Although there are various classes, class associations, and postclass activities to reinforce KIPC, grasping the correct level will be a task that must be preceded.

Received: December 21, 2020; $1^{\text {st }}$ Review Result: February 1, 2021; $2^{\text {nd }}$ Review Result: March 25, 2021 Accepted: April 30, 2021 
Knowledge and information includes not only the information collected through computers and the Internet, but also dealing with various types of knowledge. Processing means that all data is collected, analyzed, evaluated, and selected and utilized, and it is ultimately for learners to improve problem solving ability[1]. Therefore, this study is aimed to analyze the level of knowledge and information collection, analysis, and utilization, which are sub-elements of KIPC for college students. The research questions for this study are as follows.

1) What are the demographical characteristics of college students related to knowledge and information competency?

2) What is the level of college students' ability to collect knowledge and information?

3) What is the level of college students' ability to analyze knowledge and information?

4) What is the level of college students' ability to use knowledge and information?

\section{Theoretical Supports}

\subsection{Intelligent Information Society and Knowledge and Information Competency}

In the intelligent information society, people who will lead the future are encouraged to develop core competencies throughout the educational world. In line with this, the National Curriculum of Korea revised in 2015 presented six core competencies; "self-management competency, knowledge information processing competency, creativity thinking competency, aesthetic emotional competency, communication competency, and community competency". It emphasized the need for the research on knowledge and information processing competency and investigated the relationship between the educational curriculum achievement standards and communication competence among the six core competencies[2].

In accordance with the educational society's needs on the core competencies, the Korea Institute of Engineering Education Certification (KIEEC), which is Korean institution of the Accrediting Institution for Evaluation and Certification of Engineering Education (refers to http://www.abeek.or.kr/), presents standards for educational programs in the fields of engineering and implements the certification and consultation for universities[3]. Many universities have set engineering programs, expecting learning outcomes to reflect the needs of members of industries and changes in the social environment for engineering education. In particular, the Korea Institute of Engineering Education Accreditation has set and suggested learning outcomes for KIPC, regarding KIPC as one of the core competencies. Since most of Korean universities are conducting engineering programs, they are preparing specific performance standards and scoring standards (i.e. rubric) for KIPC. However, it is challenging for humanities and social science students to strengthen the KIPC, thus each university provides convergence liberal arts courses related to ICT and AI and various 4th industrial revolution, referring the courses provided by the National Institute for Lifelong Education (refers to http://www.kmooc.kr/)[4].

Along with the importance of the KIPC demands emerged, teachers' perceptions and the actual status of their classes are investigated. As a result, it was confirmed that although teachers sympathize with the importance of KIPC and recognize it in connection with the goal of cultivating scientific competence in the information society, there are not many cases of practicing KIPC in class. Thus, to improve these points, it is necessary to expand the meaning of scientific inquiry in each subject class, consider the method of linking with other subjects, and develop a teaching and learning method that considers competency characteristics[5].

It is proposed that a data-based scientific inquiry model can cultivate and examine KIPC, which is the core competency of a knowledge and information society, in the context of scientific inquiry. In the study, a teaching-learning model and a teaching strategy were redeveloped based on the resource-based learning theory[6]. According to [7], resource-based learning is a learner-centered instructional design 
theory that emphasizes how learners actively participate, organize, and share information. The importance of KIPC is being emphasized even more as it improves. It is proposed that resource-based learning is necessary to improve awareness of the learning function as a lifelong learner through the collection and selection of knowledge in a knowledge and information society, so that the role of basic education for lifelong learning can be highly expected[6]. On the other hand, the study researched the conceptual framework of digital literacy education to improve communication competencies that are important to humanities students. It can be seen that cultivating KIPC to facilitate creative production is necessary in the educational environment as it raises communication competency, creating synergy[8].

\subsection{Factors of Knowledge and Information Competency}

The previous study presented how the elements of KIPC are structured in students' scientific inquiry process and analyzed what difficulties students face in terms of KIPC. As a result of the study, three common elements of various knowledge and information competencies were found that they include information collection elements, information analysis elements, and information utilization elements [3]. Specifically, the elements of information collection were observed throughout the course of the inquiry, the elements of information analysis were observed at the stage of hypothesis setting, analysis of inquiry results, and sharing of inquiry results, and the elements of information use were identified in the creation of inquiry reports and posters. In addition, the difficulties faced by students in each competency are the certainty of information collection in information collection, systemicity of search strategies, securing reliability in information analysis, use of analysis programs, information transformation, interpretation of linked information, and information. Difficulties were revealed in organizing and effective expression skills. Furthermore, it was confirmed that improving KIPC in science subjects has the potential to increase scientific inquiry performance. Therefore, in order to overcome the difficulties encountered in the science search process, systematic education on information collection methods and cooperation with information education were encouraged, suggesting that education using ICT in science subjects is necessary. In addition, it emphasized the necessity of followup education on how to write a report that conveys information persuasively, education on expression methods that can utilize visual thinking, and policy studies[9].

The study on the effect of using educational information devices on learning strategies and selfdirected learning through the mediating effect of KIPC was conducted[4]. As a result of the analysis, it was confirmed that the use of ICT media through SNS, video viewing, online lectures, and information search has a significant influence on the development of KIPC. In addition, it was found that the KIPC that can be cultivated through the use of ICT media itself has a positive effect on learning strategies and self-directed learning. In other words, these findings suggest that, although there are criticisms of side effects due to recent over-dependence and addiction to smartphones, the restriction of unconditional use of ICT media cannot be the best solution[10].

According to [3], a general measurement tool that can measure the core competencies of each subject is not applicable only to a specific subject, but applicable to measure KIPC. The KIPC is largely divided into three categories: knowledge information collection area, knowledge information processing area, and knowledge information utilization area. It was divided into nine sub-areas, including the ability required to analyze and interpret information, and the post processing ability to utilize the processed knowledge information. In addition, these 9 areas were measured through a total of 28 specific questions. It was suggested that the measurement tool developed in this way can be used by instructors as a means to help identify and analyze learners' ability to achieve, and to learners, it can be an indicator of their own competency level[11]. 


\section{Research Methods}

\subsection{Data Collection}

The KIPC was measured by the questionnaire, which was a revised and supplemented version of [11]. A total of 25 items were used for explanation, which are divided into three categories; 11 items of knowledge and information collection competency, 6 items of knowledge and information processing competency, and 8 items of knowledge and information utilization competency. Each item was measured on a 5-point Likert scale (5: totally agree $\sim 1$ : not at all). In addition, the demographic characteristics of the participants were described by major, grade, gender, and nationality. The majors were English, Japanese, and foreign language intensive education and tourism majors. The grades were classified into 1 st to 4 th graders, the genders were male and female, and nationalities were reported as Korean and international students.

[Table 1] The Composition of Questionnaire

\begin{tabular}{|c|c|c|c|c|c|}
\hline \multicolumn{2}{|c|}{ Classification } & \multirow{2}{*}{$\begin{array}{c}\text { Variation } \\
\text { Utilization of various online media, use of } \\
\text { various offline media, identification of } \\
\text { media characteristics, selection of } \\
\text { appropriate media }\end{array}$} & \multicolumn{2}{|c|}{ Items } & Scale \\
\hline \multirow{3}{*}{$\begin{array}{l}\text { Collection } \\
\text { of } \\
\text { Knowledge } \\
\quad \& \\
\text { Information }\end{array}$} & $\begin{array}{l}\text { Media } \\
\text { selection }\end{array}$ & & 4 & \multirow{3}{*}{11} & \multirow{3}{*}{$\begin{array}{l}\text { 5-point- } \\
\text { Likert Scale }\end{array}$} \\
\hline & $\begin{array}{l}\text { Range } \\
\text { setting }\end{array}$ & $\begin{array}{l}\text { Selecting the latest data, selecting key } \\
\text { keywords, setting the scope of information } \\
\text { collection }\end{array}$ & 3 & & \\
\hline & $\begin{array}{l}\text { Material } \\
\text { judgement }\end{array}$ & $\begin{array}{l}\text { Selection of collected data, judgment of } \\
\text { snowfall, judgment of reliability, judgment } \\
\text { of violation of personal information and } \\
\text { copyright }\end{array}$ & 4 & & \\
\hline \multirow{2}{*}{$\begin{array}{l}\text { Processing } \\
\text { of } \\
\text { knowledge } \\
\quad \& \\
\text { Information }\end{array}$} & Analysis & $\begin{array}{l}\text { Indicating the source of collected data, } \\
\text { systematically organizing it, and notifying it } \\
\text { into figures }\end{array}$ & 3 & \multirow{2}{*}{6} & \multirow{2}{*}{$\begin{array}{l}\text { 5-point- } \\
\text { Likert Scale }\end{array}$} \\
\hline & Interpretation & $\begin{array}{l}\text { Identify material ranking, key summary, and } \\
\text { content selection }\end{array}$ & 3 & & \\
\hline \multirow{2}{*}{$\begin{array}{l}\text { Utilization } \\
\text { of } \\
\text { knowledge } \\
\quad \& \\
\text { Information }\end{array}$} & Producing & $\begin{array}{l}\text { Select and edit the contents of the result } \\
\text { production, select the application program, } \\
\text { and produce }\end{array}$ & 3 & \multirow{2}{*}{8} & \multirow{2}{*}{$\begin{array}{l}\text { 5-point- } \\
\text { Likert Scale }\end{array}$} \\
\hline & Presenting & $\begin{array}{c}\text { Exchange of opinions, explanations, } \\
\text { feedback, sharing, and guidance on } \\
\text { outcomes }\end{array}$ & 5 & & \\
\hline \multicolumn{2}{|c|}{$\begin{array}{l}\text { Demographical } \\
\text { Characteristics of } \\
\text { Participants }\end{array}$} & Major, grade, gender, nationality & \multicolumn{2}{|c|}{4} & $\begin{array}{l}\text { Nominal } \\
\text { scale }\end{array}$ \\
\hline
\end{tabular}

\subsection{Participants}

The participants of this study were mostly divided into the tourism majors and foreign language majors, who are taking courses focusing on competency education, including knowledge and information competency. The present study selected the target students by using the convenience extraction method. Before conducting the survey, the purpose of the study and the content of the questionnaire were explained and notified to the subjects. Among the survey questionnaires collected, a total of 238 surveys were used for the analysis, excluding surveys judged to be incomplete or 
undermining reliability.

\subsection{Data Analysis}

The frequency statistics analysis was conducted to understand the demographical characteristics of participants, and descriptive statistics analysis was performed to understand the level of knowledge and information processing competency. In addition, the T-test and ANOVA was conducted to analyze whether there is a statistically significant difference in the retention level of each detailed factor of KIPC in accordance with the demographical characteristics of participants.

\section{Findings}

\subsection{Demographical Characteristics of Participants}

The demographical characteristics of the participants in this study are described as follows. As for the majors of the participants, 127 (53.4\%) majored in Tourism, 65 (27.3\%) majored in Japanese, and 46 (19.3\%) majored in English were reported respectively. In terms of grade, 95 students (39.9\%) were in the third year, 54 students $(22.7 \%)$ in the first year, 47 students $(19.7 \%)$ in the fourth year, and 42 students $(17.6 \%)$ in the second year. In terms of gender, 144 female students $(60.5 \%)$ accounted for a higher portion than 94 male students (39.5\%). In terms of nationality, Korean students dominated at 175 (73.5\%), while the international students accounted for a fairly high proportion at 63 (26.5\%).

\subsection{The Level of Knowledge and Information Processing Competency}

In the study, the level of knowledge and information competency centering on the three core competencies is as shown in [Table 2]. The knowledge and information collection capability was the highest with an average of 3.660 , followed by knowledge information analysis capability and knowledge information utilization capability. In other words, the students showed a low level of retention, although there was not much difference in their more advanced knowledge and information capabilities.

[Table 2] The sub-categories of Knowledge and Information Processing Competency

\begin{tabular}{|c|c|c|}
\hline Classification & Ranking & Mean \\
\hline $\begin{array}{c}\text { Collection of Knowledge \& } \\
\text { Information }\end{array}$ & 1 & 3.660 \\
\hline $\begin{array}{c}\text { Processing of knowledge \& } \\
\text { Information }\end{array}$ & 2 & 3.545 \\
\hline $\begin{array}{c}\text { Utilization of knowledge \& } \\
\text { Information }\end{array}$ & 3 & 3.533 \\
\hline
\end{tabular}

At the level of KIPC of students, focusing on more detailed constituent factors, as shown in [Table 3], the average and ranking were different from those of the three core competencies. Among the factors, it has the highest level of ability to select a knowledge information collection medium and to select its scope, followed by the ability to present knowledge information utilization and interpret it for knowledge information processing. Next, it was found that it has the capacity of knowledge information collection data judgment, knowledge information processing analysis, and knowledge information utilization production. In other words, it has the strongest strength in selecting the medium or range for data collection, but the ability to extract important information from the collected data and interpret and present the results is a bit insufficient. It was found that it shows a level of competence. 
[Table 3] The Characteristics of Knowledge and Information Processing Competency

\begin{tabular}{|c|c|c|c|c|c|}
\hline \multicolumn{2}{|c|}{ KIPC } & Items & M & Ranking & M \\
\hline \multirow{11}{*}{ Collecting } & \multirow{4}{*}{$\begin{array}{l}\text { Media } \\
\text { selection }\end{array}$} & Collecting data using various online media & 3.887 & \multirow{4}{*}{1} & \multirow{4}{*}{3.714} \\
\hline & & $\begin{array}{l}\text { Identifying the characteristics and strengths } \\
\text { and weaknesses of media information }\end{array}$ & 3.756 & & \\
\hline & & $\begin{array}{l}\text { Selecting the appropriate medium for } \\
\text { collecting information }\end{array}$ & 3.752 & & \\
\hline & & Utilizing various offline media & 3.462 & & \\
\hline & \multirow{3}{*}{$\begin{array}{l}\text { Range } \\
\text { settings }\end{array}$} & Selecting the latest data & 3.748 & \multirow{3}{*}{2} & \multirow{3}{*}{3.675} \\
\hline & & $\begin{array}{c}\text { Finding key keywords for information } \\
\text { search }\end{array}$ & 3.693 & & \\
\hline & & $\begin{array}{l}\text { Setting the scope of data collection and } \\
\text { information search }\end{array}$ & 3.584 & & \\
\hline & \multirow{4}{*}{$\begin{array}{l}\text { Material } \\
\text { judgment }\end{array}$} & Selecting materials to help solve problems & 3.807 & \multirow{4}{*}{5} & \multirow{4}{*}{3.593} \\
\hline & & $\begin{array}{l}\text { Determining the appropriateness of the } \\
\text { collected data }\end{array}$ & 3.723 & & \\
\hline & & Judging the reliability of collected data & 3.471 & & \\
\hline & & $\begin{array}{l}\text { Determining personal information and } \\
\text { copyright violation of collected data }\end{array}$ & 3.382 & & \\
\hline \multirow{6}{*}{ Processing } & \multirow{3}{*}{ Analysis } & $\begin{array}{l}\text { Arranging the source of collected data and } \\
\text { indicating it correctly }\end{array}$ & 3.664 & \multirow{3}{*}{6} & \multirow{3}{*}{3.528} \\
\hline & & Systematic organization of collected data & 3.580 & & \\
\hline & & $\begin{array}{l}\text { Arrangement of transformations such as } \\
\text { graphs of collected data }\end{array}$ & 3.340 & & \\
\hline & \multirow{3}{*}{ Translation } & Prioritizing material prioritization & 3.677 & \multirow{3}{*}{4} & \multirow{3}{*}{3.66} \\
\hline & & Summarizing key material content & 3.656 & & \\
\hline & & Data (content) screening for appropriateness & 3.651 & & \\
\hline \multirow{8}{*}{ Utilization } & \multirow{3}{*}{ Producing } & $\begin{array}{l}\text { Selecting and editing content required for } \\
\text { production }\end{array}$ & 3.613 & \multirow{3}{*}{7} & \multirow{3}{*}{3.429} \\
\hline & & $\begin{array}{l}\text { Selecting the program required to produce } \\
\text { the result }\end{array}$ & 3.378 & & \\
\hline & & Producing outputs using various programs & 3.294 & & \\
\hline & \multirow{5}{*}{ Presenting } & $\begin{array}{l}\text { Communicating with others about the } \\
\text { outcome }\end{array}$ & 3.769 & \multirow{5}{*}{3} & \multirow{5}{*}{3.63} \\
\hline & & Explaining the outcome to others & 3.656 & & \\
\hline & & Feedback Q\&A on shared outcomes & 3.643 & & \\
\hline & & $\begin{array}{l}\text { Sharing the results produced by using SNS, } \\
\text { etc. }\end{array}$ & 3.571 & & \\
\hline & & Informing others about the outcome & 3.546 & & \\
\hline
\end{tabular}

Next, more specific contents of each constituent factor for students' knowledge and information competency are discussed as follows. First, in terms of media selection for knowledge information collection, using online media has the strongest point of collecting data. Other strong competencies are understanding strong and weak points of online media, online media selection and offline media utilization in order. In other words, it was found that online media utilization is higher than offline media one. Second, in setting the scope of knowledge information collection, students show the strength on the selection of the latest data, but it appeared at a relatively low level when it comes to scope setting of information search. That is, it is more difficult to choose keywords and scope setting of information 
search rather than to select the latest data. Third, in presenting knowledge information utilization, it represents the capability to exchange opinions with other people was the highest to present the collected data in the use of knowledge information. Following competences are explanation of the outcome, feedback, SNS sharing and easy guideline in order. It showed that the stronger the information sharing nature of the outcome, the lower the competency level. The capability to exchange opinions with other people was the highest to present the collected data in the use of knowledge information, and the capability to determine priorities was the highest to interpret the collected knowledge information. Fourth, the capability to determine priorities was the highest to interpret the collected knowledge information in knowledge information processing analysis. Following competencies are the capability to organize data, key materials, and the capability to identify data. In others words, it was found that they felt relatively more difficult to organize and select data than to judge the importance of the data. Fifth, in determining knowledge and information data collection, the capability to select collected data was the strongest. Following competences are the capability to judge appropriateness of data, reliability of data source, and whether or not the data was legally violated. In other words, it was found that there was a relative difficulty in determining the public performance of the data after selecting the necessary data. Sixth, in the analysis of knowledge and information processing, it was found that it showed the strongest point in the interpretation of data sources, and the ability of systematically organizing data and graphical representation of data was in order. In other words, it is judged that it will be more difficult to objectify the analyzed data more easily. Seventh, in the production activities to use knowledge information, it was found that the capability to select and edit the appropriate content for the production of the result was reported as the highest, and the capability to select a program for producing results, and then to produce outputs using programs in order. In other words, it was found that the relative competency was insufficient in selecting and producing programs for the production of the results rather than editing results.

\subsection{Results of T-test among the KIPC and Demographical Characteristics}

There was no significant difference in KIPC according to grades for all constituent factors as shown in [Table 4]. In other words, it was confirmed that the knowledge and information competency was not related to the grade level.

[Table 4] Results of T-test in KIPC according to Grades

\begin{tabular}{|c|c|c|c|c|c|c|c|}
\hline Grade & $\begin{array}{c}\text { Setting the } \\
\text { scope of } \\
\text { knowledge } \\
\text { information } \\
\text { collection }\end{array}$ & $\begin{array}{c}\text { Selecting } \\
\text { knowledge } \\
\text { information } \\
\text { collection } \\
\text { medium }\end{array}$ & $\begin{array}{c}\text { Judging } \\
\text { knowledge } \\
\text { information } \\
\text { collection data }\end{array}$ & $\begin{array}{c}\text { Analyzing } \\
\text { knowledge } \\
\text { information } \\
\text { processing }\end{array}$ & $\begin{array}{c}\text { Interpreting } \\
\text { knowledge } \\
\text { information } \\
\text { processing }\end{array}$ & $\begin{array}{c}\text { Producing } \\
\text { knowledge } \\
\text { information } \\
\text { utilization }\end{array}$ & $\begin{array}{c}\text { Presenting the } \\
\text { use of } \\
\text { knowledge } \\
\text { information }\end{array}$ \\
\hline 1st & 3.661 & 3.792 & 3.569 & 3.549 & 3.667 & 3.444 & 3.578 \\
3rd & 3.730 & 3.744 & 3.708 & 3.468 & 3.738 & 3.484 & 3.724 \\
4 th & 3.646 & 3.679 & 3.592 & 3.568 & 3.691 & 3.375 & 3.646 \\
\hline & 3.702 & 3.670 & 3.532 & 3.475 & 3.525 & 3.468 & 3.609 \\
\hline & $\begin{array}{c}\mathrm{F}=.256 \\
\mathrm{p}=.894\end{array}$ & $\begin{array}{c}\mathrm{F}=.570 \\
\mathrm{p}=.683\end{array}$ & $\mathrm{~F}=.762 \mathrm{p}=.552$ & $\mathrm{~F}=.461 \mathrm{p}=.759$ & $\begin{array}{c}\mathrm{F}=1.210 \\
\mathrm{p}=.387\end{array}$ & $\mathrm{~F}=.485 \mathrm{p}=.782$ & $\mathrm{~F}=.552 \mathrm{p}=.719$ \\
\hline
\end{tabular}

As shown in [Table 5], there was no significant difference in knowledge and information competency according to gender for most of the constituent factors, but a significant difference in knowledge and information processing analysis competency was derived. It was found that women had a somewhat higher level of knowledge and information processing capability than men. In other words, it is judged 
that female students have a stronger ability to systematically organize and objectify data.

[Table 5] Results of T-test in KIPC according to Gender

\begin{tabular}{|c|c|c|c|c|c|c|c|}
\hline Gender & $\begin{array}{c}\text { Setting the } \\
\text { scope of } \\
\text { knowledge } \\
\text { information } \\
\text { collection }\end{array}$ & $\begin{array}{c}\text { Selecting } \\
\text { knowledge } \\
\text { information } \\
\text { collection } \\
\text { medium }\end{array}$ & $\begin{array}{c}\text { Judging } \\
\text { knowledge } \\
\text { information } \\
\text { collection data }\end{array}$ & $\begin{array}{c}\text { Analyzing } \\
\text { knowledge } \\
\text { information } \\
\text { processing }\end{array}$ & $\begin{array}{c}\text { Interpreting } \\
\text { knowledge } \\
\text { information } \\
\text { processing }\end{array}$ & $\begin{array}{c}\text { Producing } \\
\text { knowledge } \\
\text { information } \\
\text { utilization }\end{array}$ & $\begin{array}{c}\text { Presenting the } \\
\text { use of } \\
\text { knowledge } \\
\text { information }\end{array}$ \\
\hline Male & 3.663 & 3.657 & 3.426 & 3.596 & 3.645 & 3.358 & 3.581 \\
Female & 3.683 & 3.752 & 3.595 & 3.595 & 3.671 & 3.475 & 3.674 \\
\hline- & $\begin{array}{c}t=.231 \\
p=.818\end{array}$ & $t=1.164 p=.246$ & $\begin{array}{c}t=2.062 \\
p=.040^{*}\end{array}$ & $t=.003 p=.997$ & $t=.309 p=.757$ & $t=1.318 p=.189$ & $t=1.095 p=.275$ \\
\hline${ }^{*} p<.05$
\end{tabular}

Knowledge and information competency according to nationality was found to have significant differences in all constituent factors as suggested in [Table 6]. It was found that all Korean students have higher knowledge and information capabilities than the international students studying together. In other words, it is judged that Korean students show more strength in knowledge and information capabilities.

[Table 6] Results of T-test in KIPC according to Nationality

\begin{tabular}{|c|c|c|c|c|c|c|c|}
\hline Nationality & $\begin{array}{c}\text { Setting the } \\
\text { scope of } \\
\text { knowledge } \\
\text { information } \\
\text { collection }\end{array}$ & $\begin{array}{c}\text { Selecting } \\
\text { knowledge } \\
\text { information } \\
\text { collection } \\
\text { medium }\end{array}$ & $\begin{array}{c}\text { Judging } \\
\text { knowledge } \\
\text { information } \\
\text { collection data }\end{array}$ & $\begin{array}{c}\text { Analyzing } \\
\text { knowledge } \\
\text { information } \\
\text { processing }\end{array}$ & $\begin{array}{c}\text { Interpreting } \\
\text { knowledge } \\
\text { information } \\
\text { processing }\end{array}$ & $\begin{array}{c}\text { Producing } \\
\text { knowledge } \\
\text { information } \\
\text { utilization }\end{array}$ & $\begin{array}{c}\text { Presenting the } \\
\text { use of } \\
\text { knowledge } \\
\text { information }\end{array}$ \\
\hline Korean & 3.823 & 3.834 & 3.701 & 3.613 & 3.783 & 3.490 & 3.746 \\
Foreigner & 3.265 & 3.381 & 3.302 & 3.291 & 3.323 & 3.259 & 3.333 \\
\hline - & $\begin{array}{c}t=6.378 \\
p=.000^{* *}\end{array}$ & $\begin{array}{c}t=5.298 \\
p=.000^{* * *}\end{array}$ & $\begin{array}{c}t=4.730 \\
p=.000^{* * *}\end{array}$ & $\begin{array}{c}t=3.605 \\
p=.000^{* * *}\end{array}$ & $\begin{array}{c}t=5.238 \\
p=.000^{* * *}\end{array}$ & $\begin{array}{c}t=2.373 \\
p=.018^{*}\end{array}$ & $\begin{array}{c}t=4.579 \\
p=.000^{* * *}\end{array}$ \\
\hline
\end{tabular}

\section{Conclusion}

The present study examined the level of KIPC of university students of Korea and proposed class activities to strengthen the competency. Firstly, the level of KIPC didn't show the difference in accordance with the grades of the participants, but there was a significant difference of knowledge and information processing in terms of gender and nationality. Female Korean students showed the higher KICP level than male and other international students in Korea. In addition, for setting the scope of knowledge and information collection, most students select and use the latest data. The ability to exchange opinions with other people was the highest in the ability to present the data collected in the use of knowledge and information, and the ability to determine priorities was the highest in the ability to interpret the collected knowledge information. Furthermore, the ability to judge the data has the strength to select the data that can be helpful in solving tasks among the collected data, and the knowledge and information analysis shows that the ability to organize the sources of the collected data and mark them correctly. In the production activities using knowledge and information, it was found that the ability to select and edit the content necessary for the production of the result was the highest.

As mentioned in the previous study [4], the present study found that students use a lot of online media such as the Internet, ebook, video clips and SNS as for a medium for collecting knowledge information. 
Thus implementing several online based media is encouraged in the classroom. As a medium for collecting knowledge information, various online media such as the Internet, ebook, video, and SNS were used extensively, and in setting the scope of knowledge information collection, the latest data were selected and used. The capability to exchange opinions with other people was the highest to present the collected data in the use of knowledge information, and the capability to determine priorities was the highest to interpret the collected knowledge information. In addition, the capability to judge the data has the strength to select the data that can be helpful in solving the task among the collected data, and the knowledge information analysis shows that the capability to organize and correctly mark the sources of the collected data is high. In the production activities to use knowledge information, it was found that the capability to select and edit the appropriate content for the production of the result was reported as the highest.

Next, it was found that the level of knowledge and information competency of college students was slightly higher than that of normal, indicating that education is necessary to raise the knowledge and information competency to a satisfactory level. In addition, it was confirmed that customized education was necessary in consideration of gender differences and nationalities. If a class activity that can strengthen the knowledge information processing capability of college students is proposed, an online medium is introduced to induce active learner participation in performing individual and team assignments, and based on this, an online medium is introduced as like the suggestion by [8]. Instructors could use small group activities that can provide opportunities for communication. In the case of flipped learning, a class model suitable for these class activities is provided, so it is a team-based activity that proposes a knowledge information collection activity using various online media for pre-class activities, and analyzes and utilizes the collected information. If this method is used during class, it will be possible to conduct a class suitable for the level of knowledge and information processing capability of university student learners, and to ensure that class activities reinforce core competencies. In short, an online medium is introduced to induce active learner participation in individual and team assignments, and the study suggests small group activities are suitable to provide opportunities for communication.

However, the present study was conducted on students of a specific university, so there is a limit to generalization of the results of this study. Therefore, it is necessary to further expand the target in future studies. In addition, since this study focused on grasping the level of knowledge and information competency of college students and analyzing the difference in demographic aspects, future research is needed to verify the practical relationship with the outcome factors and to see what effect there is through the level of knowledge and information competency.

\section{References}

[1] National Research Council, National science education standards, National Academy Press, (1996)

[2] http://www.abeek.or.kr/intro

[3] Jaehong Jang, Suyoun Kim, Inwoo Park, Development of knowledge and information processing competency measurement scale for elementary school students, EDUCATIONAL RESEARCH, (2020), Vol.78, pp.9-30, DOI : 10.17253/swueri.2020.78..001

[4] Hee Bae Kim, Jae-Hong Jang, Inwoo Park, A study on mediating effects of elementary students' knowledge and information processing competency of the effects of the use of ICT on learning strategies and self-directed learning, The Korean Journal of Educational Methodology Studies, (2019), Vol.31, No.4, pp.767-784, http://dx.doi.org/10.17927/tkjems.2019.31.4.767

[5] In-Hwa Lee, The Sub-Elements of 'Communication Competency' as Core Competence Reflected in the 2015 Revised Curriculum, The Journal of Curriculum and Evaluation, (2019), Vol.22, No,3, pp.1-29, DOI: 
https://doi.org/10.29221/jce.2019.22.3.1

[6] http://www.kmooc.kr/about_intro/

[7] Sunhee Park, Younkyung Seo, Jihyun Byun, A study on the conceptual framework of digital literacy education for the improvement of communicative competence, Journal of Cyber Education, (2013), Vol.7, No,1, pp.95-110.

[8] G. C. Rakes, Using the internet as a tool in a resource-based learning environment, Educational Technology, (1996), Vol.36, No.5, pp.52-56.

[9] Mihyun Son, Development model and strategy of data-driven science inquiry for cultivating the knowledgeinformation-processing-competency, Seoul National University, Doctor dissertation, (2020)

[10] Mihyun Son, Daehong Jeong, A Study of Science teachers' perception on knowledge information processing competency, Journal of the Korean Association for Science Education, (2018), Vol.38, No,5, pp.693-703, http://dx.doi.org/10.14697/jkase.2018.38.5.693

[11] Mihyun Son, Daehong Jeong, Jeongwoo Son, Analysis of middle school students' difficulties in science inquiry activity in view of knowledge and information processing competence, Journal of the Korean Association for Science Education, (2018), Vol.38, No.3, pp.441-449, https://doi.org/10.14697/jkase.2018.38.3.441 